\title{
Untrue to One's Own Self Sartre's The Transcendence of the Ego
}

IKER GARCIA

While recent scholarship has increasingly succeeded in making a case for the importance of The Transcendence of the Ego (TE), Sartre's first substantial philosophical publication, different approaches up to now seem to share the same twofold methodological premise. Since TE's explicit object of philosophical concern is the self, the assumption seems to be that philosophical commentary must equally focus, first, on the notion of the self, and, second, on what Sartre explicitly says about it. To be sure, commentators are not unaware that the notion of the self, as discussed in $T E$, is deeply connected with a wide variety of other notions of such philosophical importance as consciousness, personal identity, reflection, intentionality, temporality, contingency, freedom, the possibility of an ethics, and so on. Thus, none of these notions fail to receive serious attention in two recent and important contributions on TE, Stephen Priest's The Subject in Question, the first English monograph on TE, and Vincent De Coorebyter's Sartre Face à la Phénoménologie: Autour de "L’intentionnalité" et de "La Transcendance de l'Ego", a remarkable piece of scholarship on early Sartre's reception of Husserlian phenomenology. Now although these two scholar contributions display two quite different approaches to $T E$, the common twofold working assumption remains that the notions indicated above are best elucidated by, first, focusing on the central notion of the self, and, second, assessing Sartre by mostly considering $T E$ according to what it explicitly states. Thus, Priest indicates: "I have written the book so that it can be read in two ways. On the one hand, it is a critical commentary which tracks Sartre's Transcendence of the Ego chapter by chapter. ... On the other hand, the book ... may be read as an argumentative analysis of [Husserl's and Sartre's] disagreement over the self" (Priest 2000: viii). For his part, and although prima facie less clearly 
committed to the twofold premise indicated, De Coorebyter writes: "[C]ette ambivalence [of Sartre in 1939 regarding his own theses defended in $T E]$ impose une démarche interprétative qui respecte aussi bien les constantes de la pensée sartrienne que les repentirs [of Sartre about some of the theses defended in TE] manifestés à partir de 1939. Pour atteindre ce double objectif, il faut retrouver l'origine des repentirs dans la manière même dont La transcendance de l'Ego s'élève et accède aux thèses jamais reniées depuis 1934, à savoir l'autonomie de la conscience irréfléchie et la transcendance du moi psychique." (De Coorebyter 2004: 173-174, italics by De Coorebyter himself $)^{1}$

Now although the acceptance of the twofold methodological premise indicated above is hardly disputable, given that Sartre's focus of concern in $T E$ is the self and that TE's most important philosophical results are, at least prima facie, its explicit theses, this does not mean that other approaches are not possible and equally desirable. Thus, one might concentrate on one notion of philosophical importance not discussed by Sartre explicitly and try to establish interesting results regarding Sartre on both that notion and the self by drawing, moreover, on what Sartre does not explicitly say (but is arguably committed to). Given that Sartre's first philosophical publication is so clearly focused on one single philosophical concept, a feature that the secondary literature has for the most part mimicked, an approach not focusing on this concept, or at least not primarily, could prove a new, helpful way of thinking about TE.

In this paper, I shall thus consider Sartre's insights on the self found in $T E$ without, however, concentrating primarily on the notion of the self. Instead, I shall focus on the notion of truth, or rather, truth-missing. This move has two goals in mind, a rather modest one and a more ambitious one. First, I want to show how Sartre's well-known insights on the self can be exposed and enjoyed anew from a different angle than the usual ones, namely, that of truth, rather than the more customary ones of consciousness and personal identity. Although in this regard I shall not say anything new of substance, it is my hope that my approach will help to make sense of Sartre's claims on the self as much as customary expositions, and thus spark further interest in Sartre's first philosophical publication. Second, I want to suggest that in TE, Sartre is much less interested in the self per se than it is usually assumed. Rather, my thesis goes, Sartre is concerned, in equal or bigger measure, in exploring ways in which we can miss the truth about ourselves. In this light, Sartre's well-known claim that the self is transcendent to conscious- 
ness could gain new significance. Although this thesis cannot be defended in this paper, it is my hope that my analysis of TE in terms of truth and truth-missing can at least help to make it plausible and pave the way for its full-fledged defense in future contributions.

In order to fulfill these two goals, I shall consider what I will call "statements about one's own self." By "statements about one's own self" I shall mean statements of the form "I ...", where the predicate of the statement is meant to express things that are true of what is evidently given to consciousness in reflection ("in introspection," psychologically speaking). Examples of what I call statements about one's own self include "I hate Peter," "I love Mary," "I doubt," "I think," etc. Next, I shall raise two questions regarding the truth of those statements: 1) according to the Sartre of TE, can statements about one's own self be, in the final analysis, true, and 2) according to the Sartre of $T E$, is there a sense in which statements about one's own self can be said to miss the truth in a philosophically interesting way? Finally, I shall respond to these questions by showing that $T E$ can be read as involving the following three upshots. 1) Like statements about many other entities, although arguably not all conceivable entities, statements about one's own self can, in the final philosophical analysis, be true. 2) More significantly, and perhaps unlike statements about other entities, there is a sense in which statements about one's own self can miss the truth even when they are (by hypothesis) true. 3) More precisely, there are various senses, not just one, in which statements about one's own self can miss the truth, even when they are (by hypothesis) true. How they miss the truth depends on the different level of philosophical analysis at which we take Sartre to be working.

\section{TE: A Summary}

TE's exoteric chief thesis is well-known. In opposition to both Descartes and Kant, among others, but above all to Husserl, Sartre claims that there is no self in consciousness as the subject of our conscious acts, "neither formally nor materially" (Sartre 2004: 1). Instead, Sartre boldly claims, the self "is outside, in the world; it is a being in the world, like the Ego [self] of another" (Sartre 2004: 1). ${ }^{2}$ What exactly does Sartre mean by this, and what is his rationale for holding such a prima facie bizarre view?

According to Sartre, Husserl's ground-breaking conception of consciousness in terms of intentionality renders superfluous the 
notion of a unifying self in consciousness (Sartre 2004: 7). Since consciousness' defining feature is its being conscious of something, Sartre argues, whatever consciousness happens to be conscious of plays the unifying role. Thus, the unifying principle of my different consciousnesses by which, for example, I perceive a chair, is the unity of the chair itself as an object of perception, not something "in me" that unifies these different consciousnesses (Sartre 2004: 6). What is more, the unity of the object allowing for the unity of consciousness renders a unified self possible rather than the other way round (Sartre 2004: 7).

Sartre draws upon Husserl's notion of intentionality to advance one of his early major claims: the first and most fundamental mode in which consciousness is conscious of itself is not reflective, but unreflective. According to Sartre, by being conscious of an object, consciousness is at the same time and by the same stroke conscious of itself (Sartre 2004: 7; 8). This may sound somewhat unintuitive at first sight. When I am conscious of an object, I am apparently conscious only of the object, not of myself. But this prima facie implausibility results from mistakenly assuming that only in reflection can consciousness be conscious of itself. There is of course no question that, in reflection, consciousness is conscious of itself. The mistake is, according to Sartre, to see in reflection the only or the original mode in which this can happen. Against the view that reflection is the only mode in which consciousness is conscious of itself, Sartre argues that unreflective consciousness of an object is conscious of itself too. In being conscious of the object, consciousness is simultaneously conscious of itself as being conscious of the object. Sartre grants that in this case, consciousness is non-positionally conscious of itself: it does not take itself as the object of consciousness. But this circumstance does not make consciousness less self-conscious (Sartre 2004: 8; 11). Against the view that reflection is the original mode in which consciousness is conscious of itself, Sartre argues that unreflective consciousness takes precedence over reflective consciousness: unreflective consciousness does not require a reflective consciousness to be conscious of itself, whereas reflective consciousness does require a reflected consciousness to be reflective where that reflected consciousness is non-positionally conscious of itself (Sartre 2004: 19).

Sartre's critique of the primacy of reflective consciousness effectively grounds his attack on the conception of a self in consciousness. According to Sartre, both Descartes and Husserl think that there is a 
self as the subject of any consciousness-of-something. Moreover, Descartes and Husserl take the cogito, that is, the reflective grasp of consciousness by itself (typically in the form "I think"), as the de facto proof that there is a self in consciousness, since in the cogito the self never fails to appear (Sartre 2004: 9). Sartre responds that although what is directly intuited in the cogito enjoys a privileged certainty, still the cogito, structurally considered, includes two consciousnesses, a reflecting and a reflected one (Sartre 2004: 10). The reflecting consciousness is positionally conscious of the reflected consciousness, and non-positionally conscious of itself (Sartre 2004: 10-11). But since the reflecting consciousness is non-positionally conscious of itself, the reflecting consciousness is in its turn unreflected, and thus lacks a self. In short, Sartre concludes, although Descartes and Husserl are right in claiming that the self cannot fail to appear in the cogito, the self appears only in the reflected consciousness, not in the reflecting one. In the latter, taken in isolation, there really is no self at all, just as there is no self in the unreflective consciousness of objects.

Now how does Sartre account for the presence of the self in reflection, a point on which he has agreed? Where does the self "come from," if there is no self in unreflective consciousness? Sartre's suggestion is that the self does not simply happen to appear in reflection. Rather, reflection itself makes the self appear (Sartre 2004: 11). We should not think of the self as a permanent entity, of which we are not conscious in unreflective consciousness and of which we become conscious in reflective consciousness. Rather, the self is a "volatile" pseudo-entity that reflection produces as much as intuits. So it is not true, according to Sartre, that either there is or there is not a self unqualifiedly. Against the view that there is no self, Sartre unambiguously states that the self appears and is intuitable (in reflection) (Sartre 2004: 15). Against the view that there $i$ a self, Sartre observes that only in reflective consciousness is there a self, and the self is as much constituted as contemplated by reflection (Sartre 2004: 34). In unreflective consciousness it is not the case that the self simply fails to appear. Rather, Sartre holds, there is no self at all.

So far Sartre has argued that the self is not a subject in consciousness but, rather, an object for it, and only in reflection. Now how does the self appear qua object? This question prompts TE's second fundamental insight. According to Sartre, the self does not appear in reflected consciousness all at once, in an apodictic and adequate fashion. Rather, the self appears through reflected consciousness and by 
"profiles," in a non-apodictic, inadequate fashion (Sartre 2004: 15; 16). This means that we intuit our own self in reflection roughly in the same way we perceive a physical object in perception, that is, incompletely and by successive intuitions of different aspects. According to Sartre, the self is neither reflected consciousness itself, nor an individual reflected consciousness, nor a real set of reflected consciousnesses. Instead, the self is the ideal unity of all of our (potentially infinite) reflected consciousnesses (Sartre 2004: 20-21). Finally, the self does not directly unify our reflected consciousness. Instead, the self unifies the states, actions, and qualities of reflected consciousness (Sartre 2004: 21). States and actions, in their turn, directly unify our reflected consciousnesses.

Sartre does not explicitly say what a state is supposed to be. But from his examples, notably hatred and love, plus some explanatory hints, one can gather that Sartre has in mind something like, classically speaking, passions or, in contemporary terms, emotions. The key feature of states is that they are inert. We suffer them, instead of choosing them. They are psychical passivities. Different from states, actions are chosen. In contrast to the inert nature of states, actions are spontaneous. Sartre's examples of actions are doubting, reasoning, meditating, and making a hypothesis. Qualities, finally, are intermediaries between the self, on the one hand, and states and actions, on the other. Sartre thinks of qualities as including "failings, virtues, tastes, talents, tendencies, instincts, etc." (Sartre 2004: 28). Qualities are more or less permanent features of our psychical life.

The radical difference between consciousness, on the one hand, and states, actions, qualities, and the self, on the other, is captured in the fundamental opposition between consciousness and the psychical (Sartre 2004: 28). Consciousness is impersonal (selfless), intentional spontaneity, directed "outwards" by necessity, and conscious of itself, either non-positionally or positionally. The psychical, on the contrary, is a non-intentional pseudo-spontaneity, an object for consciousness, and never conscious of itself. The psychical includes the unity of states, actions, and qualities. The self is the synthetic totality of the psychical.

\section{The Self and Truth}

With this, we have TE's explicit doctrine in a nutshell. ${ }^{3}$ Let us now focus on the issue, not posed by Sartre explicitly, regarding the truth (or lack thereof) about one's own self. What I take to be the crucial 
question can be put in this way: on the basis of TE's doctrinal content, is it possible, on final philosophical analysis, to make true statements about one's own self? Let us remember that by "statements about one's own self" I mean statements of the form "I..." where the predicate is meant to express things that are true of what is evidently given to consciousness in reflection (e.g., I hate Peter, I love Mary, I doubt, I think, etc.)

Now, addressing this question is a more complex task than it may first seem. My first claim is, indeed, that different answers can and must be given depending on the level of philosophical analysis at which we take Sartre to be working, since, my second claim goes, Sartre works at various levels of analysis, not just one. Sartre's different answers to the question whether it is possible to make true statements about one's own self might not be totally consistent among themselves. However, providing instead a single, unqualified answer would greatly simplify Sartre's position and arguably decrease its philosophical interest.

What are these different answers? I shall argue as follows. At a first level of philosophical analysis, Sartre believes that statements about one's own self can be true. At a further, second level of philosophical analysis, Sartre claims that all statements about one's own self, even when based on evident intuition, are subject to error; therefore they can always be false and thus miss the truth. At a third level of philosophical analysis, Sartre believes that, even if they happen to be true at the first two levels of analysis, all statements about one's own self miss the truth in so far as they express a relation between the subject and the predicate (the self and consciousness, respectively) that alters the original relation between them. Finally, at a fourth and final level of analysis, Sartre suggests that, again, all statements about one's own self miss the truth in a still more fundamental way: while they aim at stating things that are true of ("one's own") consciousness, they state things that are true of a pseudo-object, the self, which is, instead, a (deceptive) representation of consciousness.

Taken together, my four answers shall allow me to claim that, according to Sartre, there is an important sense (or rather, three important senses) in which statements about one's own self, while true at face value, can miss the truth in a philosophically interesting way.

\section{First Level of Analysis}

Suppose I am sitting at my desk, perceiving a pen. Can we take the statement "I am perceiving a pen" (uttered by me in the indicated circumstances) to be true? This simple question, odd from the point 
of view of common sense, encapsulates the philosophical problem about one's own self and the truth (or lack thereof) of statements about it. Common sense takes for granted that, given the indicated circumstances, the statement "I am perceiving a pen" is (non-controversially) true. However, the question above does not ask whether $\mathrm{I}$, as opposed to someone else, am in fact perceiving a pen. The question asks, rather, whether there being perceptual consciousness of a pen warrants the truth of the statement " $I$ am perceiving a pen" on final philosophical analysis.

At the first level of analysis I am considering, I take Sartre to hold that the statement "I am perceiving a pen" (uttered by me in the indicated circumstances) is true (or rather, can be true). I ground my claim on five interconnected points: 1) the proper circumstances apply, as far as (unreflective) consciousness is concerned: in this particular example, there is in fact perceptual consciousness of a pen. 2) Sartre endorses Descartes's and Husserl's claim that every (unreflective) consciousness, de jure and by necessity, can always become the object of a (reflecting) consciousness; if so, consciousness acquires the form of a (reflective) cogito (Sartre 2004: 16). 3) Sartre admits with Descartes and Husserl that the cogito is personal (that is, endowed with a self): in every reflective consciousness, Sartre affirms, there is a self, an "I." (Sartre 2004: 9; 11) 4) Also in agreement with Descartes and Husserl, Sartre believes that in the cogito we in fact intuit, and moreover evidently intuit, the self appearing in (or rather, through) reflected consciousness (Sartre 2004: 9). 5) Sartre claims that although the cogito transforms unreflected consciousness into a reflected one, reflected consciousness does not stop being conscious of the object it was aiming at when the consciousness was unreflected (it does not stop, in this case, perceiving a pen) (Sartre 2004: 17).

These five points simply restate Sartre's view that every unreflected consciousness can always become reflected on, with the result that an (intuitable) "I" appears through the reflected consciousness. If so, I can state, e.g., "I am perceiving a pen" at the occasion of this reflective act, a statement which for Sartre expresses the fact that a transcendent "I" appears "behind" the (reflected) perceptual consciousness of a pen. Taken to express this (and only this), the statement in question must be true for Sartre on final philosophical analysis. Now, since Sartre believes that any unreflected consciousness can de jure become reflected on, any unreflected consciousnesses can motivate a reflective act allowing for a statement of the form "I ..." (e.g., "I hate Peter," "I love Mary," "I doubt," "I 
think," "I judge that two plus two equals four," "I remember Barcelona," "I imagine a centaur," and so on). Therefore, Sartre believes that a potentially infinite number of statements about one's own self can be (non-trivially) true on final philosophical analysis.

\section{Second Level of Analysis}

Does this position commit Sartre to the stronger view that all statements about one's own self, not just some of them, are true (in the sense just indicated)? In other words: can statements about one's own self expressing what is evidently given in reflection fail to be true? Sartre suggests that both Descartes and Husserl reject this possibility as inconceivable. However, Sartre disagrees with Descartes and Husserl on this fundamental point (Sartre 2004: 15). "I am perceiving a pen" can be a true statement if I happen to be perceiving a pen, together with my making of the perception the object of a reflective act (see above, first level of analysis). However, and in opposition to Descartes and Husserl, Sartre believes that this statement can fail to be true too, even when it expresses what is evidently given in reflection. What are Sartre's reasons to defend such a prima facie implausible view?

Let us remember TE's two crucial theses. 1) The self is an object for consciousness, not a subject in it. 2) Both the self and its states, actions, and qualities, are given in reflection in a non-apodictic and non-adequate fashion. Similar to physical objects in perception, the self does not appear in reflection in one stroke and completely, but through time and partially, one aspect at a time (Sartre 2004: 23). Thesis 1) reminds us that the self is an object for consciousness and not a subject in it. Therefore, the step from " $t$ there is' consciousness of $x$ " to " $I$ am conscious of $x$ " is a problematic one: we pass from the absolutely indubitable and apodictically certain to the dubitable and non-apodictically certain. Thesis 2) entails that it is meaningful to doubt whether my own self suffers such and such state, performs such and such action, and possesses such and such quality. Similar to objects of perception, I never have my own self fully (i.e., apodictically and adequately) present before my intuition. The same goes for the self's states, actions, and qualities: these psychic unities show themselves inadequately too, even when they show themselves evidently. Thus, as Sartre insists, I cannot meaningfully doubt that (supposing the appropriate circumstances apply), e.g., Peter appears to unreflective consciousness as being, e.g., hateful (hateable, detestable). But if I pass from unreflective to reflective consciousness I can meaningfully doubt that my consciousness on the occasion of seeing 
hateful Peter is a (reflective) experience of hatred. ${ }^{4}$ For hatred is -present to my reflective consciousness in the same partial and incomplete way that, e.g., a table is present to my perceptual consciousness. And although I do not usually doubt that a perceived table is actually there, it is not meaningless to do so: the possibility of a table not being there, as misperception shows, is always conceivable. In the same way, the possibility of, e.g., hatred "not being actually there" is always conceivable even if it is apodictically certain that, e.g., Peter appears to me as being hateful. This means that the statement "I hate Peter" can always miss the truth even if it is apodictically certain that Peter appears to me as being hateful.

Let us clarify, however, the sense in which Sartre believes that truth-missing about one's own self is always possible de jure. Regarding the self, Sartre does not mean that, after all, there might be no self. The self is a dubitable, not a bypothetical entity (Sartre 2004: 31). I can doubt whether my self suffers such and such state or performs such and such action, but I can not doubt whether I have a self at all. That is, I can meaningfully doubt that I hate Peter or that I love Mary, but I can not doubt whether there is an "I" (in reflection, well understood) (Sartre 2004: 31-32). Regarding states, actions, and qualities, Sartre does not mean that I might be mistaken in apprehending what reflected consciousness evidently offers me to intuition. Rather, I can always be mistaken regarding the psychic entity of which my present reflected consciousness is one aspect. Once again, "I hate Peter" might always miss the truth despite the fact that it is indubitable for me now that Peter appears to me as being hateful. But this is not because it might be false after all that Peter appears to me as being hateful. If this circumstance holds at all, it is indubitable. What is dubitable, again, is that my present, unreflective consciousness in the presence of hateful Peter is hatred of him (once I pass from unreflective to reflective consciousness). Sartre's insight is that truth-missing about one's own self can happen because "I hate" affirms more than what is evidently given, not because it affirms something that is not given (Sartre 2004: 23-24).

This last point is important, and it entails that, at Sartre's second level of philosophical analysis statements about one's own self can miss the truth in two very different ways: a philosophically uninteresting one and a philosophically interesting one. On the one hand, truth can be (trivially) missed by stating what is not in fact given in reflection (e.g., "I hate Peter" when in fact, e.g., I like Peter). On the other hand, truth can be missed despite stating what is evidently given in reflection ("I hate Peter" on the occasion of seeing hateful 
Peter). Not surprisingly, Sartre is concerned with the latter, more interesting possibility.

All these considerations allow Sartre to claim that, de jure and not only de facto, one can always miss the truth about one's own self, even when one can evidently intuit it (Sartre 2004: 16; 22-23; 31; 44; 50).

\section{Third Level of Analysis}

We have seen that, according to Sartre, statements about one's own self can be (non-trivially) true at the first level of analysis, yet they can (non-trivially) miss the truth, even when based on evident intuition, at the second level of analysis. What I want to show now is that, for Sartre, all statements about one's own self do miss the truth even when they are true at the previous levels of analysis. According to Sartre, this happens because statements about one's own self do not simply express a logical link between the self and consciousness, but, moreover, what might be called a "causal" link between both. Now from what Sartre claims it results that the existence of this "causal" link expressed in statements about one's own self reverses, and thus falsifies, the original relation between the self and consciousness.

As we saw, Sartre believes that the self is, ultimately, a transcendent unification of all of our reflected consciousnesses. But the selfas-object, Sartre adds, does not immediately unify them. Rather, states, actions, and qualities do, and the self, in turn, unifies states, actions, and qualities. Now states, actions, and qualities do not only unify reflected consciousness, and the self does not only unify states, actions, and qualities. This unification also includes, according to Sartre, a positing of a "causal" link of production between the self and states, actions, and qualities, on the one hand, and between states, actions, and qualities and the reflected consciousnesses on the other hand (Sartre 2004: 15; 32).

This "positing," Sartre stresses, appears evidently together with the self and states, actions, and qualities themselves. It is not intuited "after inspection." The appearing of one's own self as producing a state or action is evidently given in intuition (Sartre 2004: 32; 34). There is no positing of a relation, if "positing" is taken to mean a (theoretical) choice or (purposive) act by us. In short: Sartre's suggestion is that the appearing of the self in reflection includes more than its simple presence. The self does not simply appear, but it appears moreover as producing a specific state or action which, in turn, appears as bringing about a specific consciousness-of-something. If I reflect on the occasion of seeing hateful Peter, for exam- 
ple, my self appears as producing my hatred of Peter, which, in turn, appears as bringing about my unreflective consciousness of disgust towards Peter. What is crucial here is that the appearance of the self brings with it a reversal of the original relation between self and consciousness, which entails a falsification of this original relation (Sartre 2004: 34-35).

As shown before (see section 2), for Sartre unreflective consciousness takes precedence over reflective one. This means two things: 1) unreflective consciousness is an autonomous, self-standing totality which does not need reflection to be completed; 2) unreflective consciousness comes before reflection, not only de facto, phenomenologically, but de jure, ontologically. Now reflection does not only bring about the appearance of the self, but also the "illusion" that reflective consciousness takes precedence over unreflective consciousness. This entails that reflection brings about the "illusion" that the self takes precedence over consciousness, since for Sartre reflection entails appearance of the self, and furthermore, appearance of the self as bringing about (through states and actions) such and such consciousness-of-something. The upshot of all these considerations is the following: according to Sartre, all statements about one's own self miss the truth in an important sense, even if they are true at the previous levels of analysis. At this third level of analysis, statements about one's own self miss the truth in so far as they give expression to the illusion that the self brings about a specific consciousness-ofsomething. This relation of the self to a specific consciousness-ofsomething is, according to Sartre, a falsification of the original one, which proceeds in exactly the opposite direction.

\section{Fourth Level of Analysis}

Finally, there is still a last sense in which Sartre believes that statements about one's own self miss the truth, even if they happen to be true at the previous levels of analysis. This last sense is arguably Sartre's most important one, and it can be forcefully expressed with the following ad limitem hypothesis: even if every statement I made about my own self happened to be true, even if it were so apodictically, and even if it did not implicitly express a reversal of the original relation between ("my") consciousness and my own self (assuming so per impossibile), it would still hold for Sartre (or so I shall argue) that I would miss the truth in a significant sense. Crudely put, I would miss the truth in the sense that the statement is true of my own self, but not of ("my") consciousness. ${ }^{5}$ I shall claim that this circumstance entails missing the truth because, according to Sartre, 
statements about my own self aim at stating things that are true of ("my") consciousness.

In order to understand this last sense in which truth about one's own self can be missed, we have to recall Sartre's different answers to the question what statements about one's own self express, depending on the level of philosophical analysis he is considering. Let us quickly summarize what we have so far. At the first level, statements about one's own self express the appearance of a new, transcendent object, the self, which reflecting consciousness both intuits and constitutes through (or "behind") the reflected, unreflective consciousness on the occasion of a reflective act. At this level, "I hate Peter" expresses my reflective grasp of the self through ("behind") the reflected consciousness of Peter-appearing-as-being-hateful. At the second level, statements about one's own self affirm the existence of this new object of a reflective act as a transcendent unity of my states, actions, and qualities. At this level, "I hate Peter" expresses the existence of my hatred of Peter as the unity of all of my reflected consciousnesses of Peter-appearing-as-being-hateful, and the existence of the self, in turn, as the unity of all of my hatreds (and of course, of all of my other states, actions, and qualities). Yet at a third level, statements about one's own self express the existence of the self as the source or origin of states, actions, and qualities. At this level, "I hate Peter" expresses the fact that my hatred of Peter is brought about by me, that is, that $I$ am the true, genuine agent of my hatred of Peter. What do statements about one's own self express at Sartre's fourth and last level of philosophical analysis? My claim is that, according to Sartre, statements about one's own self attempt to state things that are true of (selfless) unreflective consciousness. At this level, "I hate Peter" attempts to express the fact that "there is" (unreflective) consciousness of Peter-appearing-as-being-hateful. Since consciousness, however, cannot intuit itself qua unreflective, this attempt cannot succeed. However, the attempt of unreflective consciousness to be an intuitable object for itself does not completely fail, because consciousness does succeed in pretending to be an intuitable object for itself. The appearance of the self is precisely the result of this falsifying projection.

To make my case, I am going to show that, according to Sartre, 1) statements about one's own self attempt to predicate things that are true of consciousness rather than of one's own self. In other words, statements about one's own self attempt to predicate things that are true of unreflected consciousness, rather than of reflected consciousness. 2) Consciousness cannot "succeed" in its attempt to be an 
intuitable object for itself other than producing a representation of itself, which is precisely one's own self. 3) Statements about one's own self cannot "succeed" in its attempt to predicate things that are true of consciousness other than predicating things that are true of consciousness' representation of $i$ tself, that is, of the self.

To show that 1) holds, one only needs to consider how Sartre characterizes reflection. Sartrean reflection is consciousness' attempt at intuiting itself, rather than its effective self-intuition (as, according to Sartre, Cartesian and Husserlian reflection claims to be). However, I want to further argue that Sartrean reflection is, moreover, consciousness' attempt at intuiting itself qua unreflected, not qua reflected. The intuition of a reflected consciousness is precisely the result of consciousness' failure to perform this task.

The crucial question can be put in this way: can reflected consciousness be aimed at as such (i.e., qua reflected)? Or is reflected consciousness, rather, the result of an intention originally aimed at unreflected consciousness? It seems the latter is the case. If we originally aimed at reflected consciousness (qua reflected), reflection would miss its point, since consciousness would attempt to intuit a consciousness already intuited. The very notion of an intention originally aiming at reflected consciousness qua reflected is suspect in phenomenological terms, if not simply flawed. (Reflecting) consciousness can never aim at reflected consciousness, for this would entail that reflective consciousness has already taken place. Instead, (reflecting) consciousness aims at unreflected consciousness. The ideal of consciousness would be to intuit itself as it "truly is," that is, in its unreflective mode. Now this intention fails, and reflected consciousness is the product of this failure. We should not say, therefore, that the reflecting consciousness intuits the reflected one. We should rather say that, in reflection, consciousness intuits unreflected consciousness through a reflecting intention. If we agree that statements about one's own self attempt to state things that are true of what is evidently given in reflection, we should thus say that statements about one's own self attempt to state things that are true of unreflected consciousness, rather than of reflected consciousness. ${ }^{6}$ But this means that statements about one's own self attempt to state things that are true of (selfless) consciousness rather than of one's own self.

From this circumstance, it still does not follow that all statements about one's own self miss the truth in a fundamental sense. What is needed for this to occur is that the self is, de jure and by its own nature, a deceptive entity. Sartre is quite explicit that this is in fact the case (Sartre 2004: 15;39;48), but one should further ask what 
Sartre's reasons are for this view. Is it the bare fact that the self is a mixture of thing and conscionsness that makes it a deceptive entity or something else is needed? Sartre believes that other mixtures of thing and consciousness exist, and in fact abound, without being "perpetually deceptive" (Sartre 2004: 39). ${ }^{7}$ How does the self differ from these other mixtures of thing and consciousness? The difference is that in the case of the self, consciousness itself produces this mixture. The self is consciousness' own false self-representation (Sartre 2004: 35; 38).

If Sartre is right, statements about one's own self cannot succeed in stating things that are true of consciousness other than stating things that are true of (selfless) consciousness' own false representation, that is, of the self. In effect, statements about one's own self express things that are true of what is evidently given in reflection. Reflective consciousness, however, originally aims at intuiting selfless, unreflected consciousness, rather than reflected consciousness or one's own self. Now reflective consciousness can not do this other than by bringing about a reflected consciousness, and with it, the self. But the self, Sartre says, is consciousness' own false representation of itself. All of these claims entail that statements about one's own self can not state things that are true of selfless, unreflected consciousness but can only state things that are true of reflected consciousness, that is, consciousness endowed with a self. But since the self is consciousness' own false representation, all predication of it without exception, even if true at the previous levels of analysis, can be said to miss the truth at this fourth level of analysis.

\section{Summary}

In this paper, I have drawn on Sartre's The Transcendence of the Ego to elicit a number of ways in which, according to Sartre, statements about one's own self (statements of the form "I..." stating things that are true of what is evidently given in reflection) can be said to miss the truth in a philosophically interesting way. This possibility brings us, eventually, to the peculiar nature of the self. According to Sartre, the self is a particularly problematic entity because the self is, on final analysis, a (false) representation of (selfless) consciousness. Not only that, consciousness itself produces its own (false) representation. On the one hand, statements about one's own self can be said to be true if they predicate things that are true of what is evidently given in reflection. On the other hand, however, by predicating 
things that are true of a (false) representation of consciousness, and originally aiming at predicating things that are true of consciousness itself, they miss the truth in a significant sense.

Thanks to Bill Schroeder, Arthur Melnick, Richard Schacht, Shelley Weinberg, Dan Korman, Bruce Baugh, and an anonymous referee from Sartre Studies International. Special thanks to Sonia Lee.

IKer Garcia holds a BA in English (1996) and a BA in Philosophy (2001) from the Universitat de Barcelona, as well as a MA in Philosophy from the University of Illinois at Urbana-Champaign (2005). $\mathrm{He}$ is currently a doctoral candidate in Philosophy at the University of Illinois under the direction of William R. Schroeder. His dissertation, Truth-Missing Truth: The Case From Continental Philosophy, elicits ways in which a number of significant philosophers in the Continental tradition (Hegel, Kierkegaard, Heidegger, and Sartre) suggest that we can miss the truth despite stating or believing what is (by hypothesis) true.

\section{Notes}

1. In English, roughly: “This ambivalence [of Sartre's] necessitates an interpretative approach that respects both the constants of Sartre's thought and his misgivings [about the theses put forward in TE] that become apparent as of 1939. To accomplish this double objective, it is necessary to seek the origin of the misgivings in the very way in which The Transcendence of the Ego arrives at the theses which Sartre has never renounced since 1934, namely, the autonomy of unreflected consciousness and the transcendence of the psychic ego [moi]."

2. For the sake of English readability, I shall be using "self" when in fact Sartre uses "Ego."

3. To be exact, I have covered only part one of TE: I. The I and the me (TE, pgs. 121). I ignore by now the rest, that is, II. The constitution of the Ego and Conclusion (TE, pgs. 21-52), but I shall later on make use of it, and thus partially summarize it.

4. As Sartre vividly puts it, "It is certain that I loathe Peter [Pierre me répugne], but it is and will always remain doubtful whether I hate him [Je le haïse]." (TE, pg. 22-23) The original French makes the point more forcefully: the use of two different grammatical patterns, dative ("Peter is hateful to $m e$ ") and nominative ("I hate Peter"), conveys better than in English the fundamental difference between, 
respectively, the unreflective and the reflective consciousness regarding Peter's being hateful.

5. Another way to put this point would be to say that my whole (true) predication may well be about my own self, but not about myself. In this case, a difference between "my own self" and "myself" should, obviously, be raised. I use the former expression as I have done so far, referring to my own self, where "self" is to be understood in the way $T E$ characterizes this entity. I use the latter to refer to impersonal consciousness, again in TE's terms. A distinction between stating things that are true of "my own self" and stating things that are true of "myself" may seem spurious to non-sympathetic readers. But I take it to be fair to Sartre's view. After all, TE's major goal is to raise a neat and sharp distinction between the self and consciousness.

6. Sartre himself ambiguously oscillates between these two different planes, that of strict phenomenological description and that of doctrinal, non-phenomenological exposition. For example: "In this case (i.e., in a reflective act), the complex structure of consciousness is as follows: there is an unreflected act of reflection without I [i.e., the reflecting consciousness] which is aimed at a reflected consciousness." (Sartre 2004: 16, my italics) To say of (reflecting) consciousness that it "[aims] at a reflected consciousness" (Sartre 2004: 16, my italics) is, if meant to be a strict phenomenological description of what is given, somewhat misleading, if not simply wrong. Or else, there is lack of terminological accuracy. Take the example of imagination. According to Sartre, in imagination we do not aim at the image of an object, but at the object itself, through an imaging intention: "[W]hen I produce in myself an image of Pierre, it is Pierre who is the object of my current consciousness. ... The imaging consciousness that I have of Pierre is not a consciousness of an image of Pierre: Pierre is directly reached, my attention is not directed at an image, but at an object." (Sartre 2004 [b]: 6-7) Thus, it is wrong to say of imaging consciousness that it aims at an imagined object. Rather, imaging consciousness aims at the object itself through an imaging intention. This means that the object is not aimed as qua imagined, but qua object, through an imaging intention. Analogously, we should say that reflecting consciousness aims at consciousness qua unreflected, rather than qua reflected, if Sartre is right that the former, not the latter, is the original mode of consciousness.

7. Sartre himself gives the example of mimicry (Sartre 2004: 35).

\section{References}

De Coorebyter, Vincent (2000), Sartre Face à la Phénoménologie: Autour de "L'intentionalité" et de "La Transcendance de l'Ego" (Brussels: Ousia)

Priest, Stephen (2000), The Subject in Question: Sartre's Critique of Husserl in The Transcendence of the Ego (London and New York: Routledge) 
Sartre, Jean-Paul [1937] [1965] (2004), The Transcendence of the Ego, translated by Andrew Brown, with an introduction by Sarah Richmond (London and New York: Routledge) [1940] (2004) [b] The Imaginary, translated by Jonathan Webber (London and New York: Routledge) 